Arq. Bras. Med. Vet. Zootec., v.56, n.2, p.202-206, 2004

\title{
Avaliação econômica de bezerros alimentados com colostro fermentado, associado ao óleo de soja e zeranol
}

[Economic evaluation of calves fed fermented colostrum, associated with soybean oil and zeranol]

\author{
A.L.M. Castro ${ }^{1}$, W.E. Campos $^{2}$, A.B. Mancio $^{3}$, O.F. Campos ${ }^{4}$ \\ ${ }^{1}$ Faculdades Integradas do Planalto Central \\ Parque Rio Branco, Valparaíso 11 \\ 72870-000 - Valparaíso, GO \\ ${ }^{2}$ Doutorando pela EV-UFMG - Belo Horizonte \\ ${ }^{3}$ Universidade Federal de Viçosa - Viçosa \\ ${ }^{4}$ Embrapa Gado de Leite - Juiz de Fora
}

\section{RESUMO}

Utilizaram-se 40 bezerros Holandês $\times$ Zebu com objetivo de avaliar a viabilidade econômica da utilização do colostro fermentado, do óleo de soja e do zeranol em bezerros entre o $15^{\circ}$ e o $60^{\circ}$ dia de vida. Diariamente, foram fornecidos $1,5 \mathrm{~kg}$ de concentrado contendo $23 \%$ de proteína bruta, feno de tifton (Cynodon dactylon) à vontade e três litros de leite ou colostro fermentado. Considerando as despesas de criação e as receitas geradas, verificou-se menor custo dos animais tratados com colostro fermentado. Esse resultado, associado ao bom desempenho obtido, demonstrou que o colostro fermentado é eficiente como substituto do leite para bezerros em fase de aleitamento, gerando maior lucratividade.

Palavras-chave: bezerros, alimentação, óleo, zeranol, custo, rentabilidade

\begin{abstract}
Profitability of fermented colostrum, soybean oil and zeranol were evaluated in 40 Holstein $\times$ Zebu calves from 15 to 60 days of age. They were fed a concentrate with $23 \%$ crude protein, restricted at amount of $1.5 \mathrm{~kg} /$ day, ad libitum Tifton hay (Cynodon dactylon) and three liters of milk or fermented colostrum. Considering the nursing expenses and the incomes, the results showed lower costs for animals fed with fermented colostrum. This result associated with animals performance showed that fermented colostrum is efficient for suckling calves, allowing higher profitability.
\end{abstract}

Keywords: calves, feeding, fat, zeranol, cost, profitability

\section{INTRODUÇÃO}

O avanço das técnicas de alimentação e manejo na pecuária leiteira, principalmente relacionadas à criação de bezerros, tem levado criadores a buscarem alternativas economicamente viáveis para essa exploração. No Brasil, a maioria dos machos de origem leiteira ainda não é utilizada para corte (Teixeira, 2000). A maioria dos 7,5 milhões de bezerros nascidos por ano é descartada, desperdiçando-se uma potencial fonte de renda (Caldas, 2003). Estima-se que, aproximadamente, $30 \%$ dos animais abatidos para o consumo de carne sejam oriundos de rebanhos leiteiros (A carne..., 2003).

Trabalho financiado pela FAPEMIG

Recebido para publicação em 30 de abril de 2003

Recebido para publicação, após modificações, em 1 de outubro de 2003

E-mail: alvlmc@uol.com.br 
Por se tratar de um alimento caro, o leite usado para bezerros na fase inicial da vida deve ser substituído. Uma alternativa viável é a utilização do colostro excedente na alimentação, até que os bezerros atinjam consumo mínimo de concentrado que permita o desaleitamento (Ribeiro et al., 2001b). Em propriedades onde a média de produção das vacas é elevada, o colostro pode ser obtido em quantidades adequadas (Rindisig, 1976).

Apesar de constituir alternativa para o aumento da receita na propriedade leiteira, a utilização de bezerros para produção de carne apresenta fatores limitantes. $\mathrm{O}$ uso do leite na dieta dos bezerros ocasiona desvio de recursos, diminuindo a lucratividade do sistema. Contudo, sabe-se que bezerros da raça Holandesa apresentam grande potencial para produção de carne graças à elevada taxa de ganho de peso (Biondi, 1978; Eastridge, Roseler, 2003).

Este trabalho teve o objetivo de avaliar a viabilidade econômica de utilização do colostro fermentado, do óleo de soja e do zeranol em bezerros entre o $15^{\circ}$ e o $60^{\circ}$ dia de vida.

\section{MATERIAL E MÉTODOS}

Os tratamentos experimentais foram constituídos de quatro dietas líquidas, com ou sem a aplicação do zeranol, administradas do $15^{\circ}$ ao $60^{\circ}$ dia de vida dos animais. Oito tratamentos (T) foram obtidos: T1- leite integral; T2- leite integral com óleo de soja; T3- leite integral e zeranol; T4leite integral com óleo de soja e zeranol; T5colostro fermentado; T6- colostro fermentado com óleo de soja; T7- colostro fermentado e zeranol; T8- colostro fermentado com óleo de soja e zeranol.

Os procedimentos experimentais foram descritos por Castro et al. (2004).

A viabilidade econômica dos tratamentos foi evidenciada pelo menor custo ou maior retorno. Estimou-se o lucro na venda da arroba dos animais considerando-se o colostro fermentado a custo zero. Os preços arbitrados para os demais itens estavam de acordo com o mercado local.

Arq. Bras. Med. Vet. Zootec., v.56, n.2, p.202-206, 2004
O custo de produção foi calculado pelo custo operacional efetivo (bezerro recém-nascido, mão-de-obra, leite, concentrado e volumoso consumidos, óleo de soja, lecitina de soja, bicarbonato de sódio, zeranol, vermífugo e complexo vitamínico $\mathrm{ADE}$ ), e os valores foram apresentados em reais.

As despesas foram constituídas pelo preço de: compra do bezerro, $\mathrm{R} \$ 15,00$, do leite, $\mathrm{R} \$ 0,24 / 1$, e do concentrado, $\mathrm{R} \$ 0,25 / \mathrm{kg}$, e mão de obra, R\$120,00/mês.

$\mathrm{O}$ custo com mão-de-obra foi calculado conforme o valor do salário mínimo vigente na época, mais encargos tributários. Adotou-se o tempo de duas horas para tratamento dos animais com leite e de quatro horas para tratamento com colostro fermentado. O maior tempo usado para o colostro se justifica pelo manuseio e higienização dos utensílios.

\section{RESULTADOS E DISCUSSÃO}

Os custos operacionais e as receitas encontramse na Tab. 1. A análise econômica reflete a situação de uma propriedade onde a produção de colostro pelas vacas excede a demanda necessária pelos bezerros. Estes resultados, associados ao desempenho obtido pelos animais tratados com colostro fermentado, comprovam a vantagem de utilização do sucedâneo em reduzir o custo de produção e viabilizar o sistema de criação de bezerros de origem leiteira para a produção comercial de carne. A avaliação dos custos operacionais encontra-se na Fig. 1.

Os tratamentos com leite integral apresentaram custo operacional médio por bezerro de $\mathrm{R} \$ 72,10$, valor 2,3 vezes superior aos tratamentos à base de colostro fermentado, média de $\mathrm{R} \$ 31,70$. Essa diferença foi atribuída, principalmente, ao custo do leite integral, que contribuiu com $62 \%$ do custo operacional de T1 a T4. T5 a T8 não apresentaram acréscimos da dieta líquida sobre o custo operacional, pois se utilizou colostro fermentado a custo zero. Os resultados refletem a fase crítica na criação de bezerros de origem leiteira destinados à produção de carne, a de aleitamento, a qual pode inviabilizar o processo (Campos, 1995; Mejía, 1995; Lucci, 1996; Ribeiro, 2001a,b). 
Tabela 1. Estimativa das receitas, custos operacionais e saldos (R\$) segundo os tratamentos utilizados em uma propriedade leiterira

\begin{tabular}{|c|c|c|c|c|c|c|c|c|c|c|}
\hline \multirow{2}{*}{ Item } & \multirow{2}{*}{ Unidade } & \multirow{2}{*}{$\begin{array}{c}\text { Preço } \\
\text { unit. }\end{array}$} & \multicolumn{8}{|c|}{ Tratamento } \\
\hline & & & $\mathrm{T} 1$ & $\mathrm{~T} 2$ & T3 & $\mathrm{T} 4$ & T5 & T6 & T7 & T8 \\
\hline \multicolumn{11}{|l|}{ 1-Despesas } \\
\hline 1.1-Bezerro & & 15,00 & 75,00 & 75,00 & 75,00 & 75,00 & 75,00 & 75,00 & 75,00 & 75,00 \\
\hline 1.2- Mão-de-obra & $\mathrm{h} / \mathrm{hom}$ & 5,00 & 18,60 & 18,60 & 18,60 & 18,60 & 27,80 & 27,80 & 27,80 & 27,80 \\
\hline 1.3-Ração & $\mathrm{kg}$ & 0,20 & 17,40 & 14,80 & 21,30 & 21,80 & 34,20 & 40,50 & 21,50 & 30,20 \\
\hline 1.4- Feno & $\mathrm{kg}$ & 0,18 & 1,90 & 1,90 & 1,90 & 1,90 & 1,90 & 1,90 & 1,90 & 1,90 \\
\hline 1.5-Dieta líquida & 1 & 0,25 & 225,0 & 225,00 & 225,00 & 225,00 & 0,0 & 0,0 & 0,0 & 0,0 \\
\hline 1.6- Óleo degomado e lecitina de soja & $\mathrm{kg}$ & 1,20 & - & 20,70 & - & 20,70 & - & 20,70 & - & 20,70 \\
\hline 1.7- Bicarbonato de sódio & $\mathrm{kg}$ & 0,535 & - & - & - & - & 4,80 & 4,80 & 4,80 & 4,80 \\
\hline 1.8-Zeranol & Dose & 1,60 & - & - & 8,00 & 8,00 & - & - & 8,00 & 8,00 \\
\hline 1.9- Vermífugo & Dose & 0,34 & 1,70 & 1,70 & 1,70 & 1,70 & 1,70 & 1,70 & 1,70 & 1,70 \\
\hline $1.10-\mathrm{ADE}$ & Dose & 0,23 & 1,30 & 1,30 & 1,30 & 1,30 & 1,3 & 1,30 & 1,30 & 1,30 \\
\hline 2- Custo total & $\mathrm{R} \$$ & - & 340,50 & 358,90 & 352,70 & 373,90 & 146,70 & 173,70 & 142,00 & 171,40 \\
\hline 3-Custo por bezerro & - & - & 68,20 & 71,80 & 70,60 & 74,80 & 29,30 & 34,70 & 28,40 & 34,30 \\
\hline 4- kg de carcaça & $\mathrm{kg}$ & - & 31,80 & 33,40 & 35,50 & 36,70 & 32,60 & 35,80 & 28,00 & 33,70 \\
\hline 5-Quantidadede@ & a & - & 2,10 & 2,30 & 2,40 & 2,50 & 2,20 & 2,40 & 1,90 & 2,20 \\
\hline 6- Receita por bezerro & - & - & 53,00 & 55,80 & 59,30 & 61,30 & 54,50 & 59,50 & 46,60 & 54,30 \\
\hline 7- Saldo & - & - & $-15,20$ & $-16,00$ & $-11,30$ & $-13,50$ & 25,20 & 24,80 & 18,20 & 20,00 \\
\hline
\end{tabular}

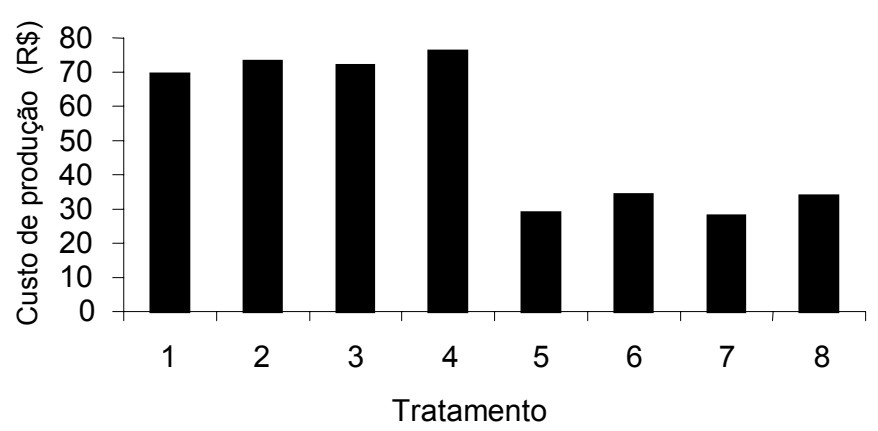

Figura 1. Estimativa dos valores médios do custo operacional por bezerro.

A redução dos custos foi superior à encontrada por Lombardi et al. (1997), 17,1\%, ao restringirem o fornecimento de leite para bezerros duas vezes na semana.

O custo do concentrado inicial em relação ao custo operacional representou $5,2 \%$ para bezerros alimentados com leite e $20,3 \%$ para os alimentados com colostro fermentado. $\mathrm{O}$ uso do colostro fermentado estimulou o consumo de ração sem onerar o custo de produção, isto é, o maior consumo de alimento sólido foi compensado pelo maior ganho de peso por $\mathrm{kg}$ de matéria seca ingerida. Resultados semelhantes foram relatados por Ribeiro et al. (2001a e b), que verificaram melhores resultados econômico e de desempenho para animais alimentados com maior proporção de concentrado.

Vasconcelos et al. (1998) verificaram aumento do custo de produção devido a maior ingestão de alimentos sólidos causada pela administração de sucedâneo comercial.

A receita de venda dos bezerros (Tab.1; item 6) revelou que o $\mathrm{T} 4$ foi $\mathrm{o}$ de melhor resultado 
( $\mathrm{R} \$ 61,30)$. A média das receitas dos tratamentos com leite integral foi de $\mathrm{R} \$ 57,30,6,7 \%$ maior que a dos tratamentos com colostro fermentado, de $\mathrm{R} \$ 53,70$. Essa vantagem é atribuída, principalmente, ao maior peso de carcaça, resultante do efeito do zeranol associado ao leite integral. Os tratamentos com leite e zeranol apresentaram receita $10,1 \%$ superior aos tratamentos somente com leite, 5,7\% superior aos tratamentos com colostro fermentado e $19,5 \%$ aos com colostro fermentado mais zeranol.

Se o produto final fosse comercializado, o uso do leite como dieta líquida resultaria em prejuízo de $\mathrm{R} \$ 15,20$, atribuído, principalmente, ao elevado custo da dieta líquida, associado ao menor peso da carcaça. A inclusão do óleo de soja ao leite resultou em maior peso da carcaça graças ao incremento energético, sem aumentar a ingestão de concentrado. Essa associação não foi suficiente para promover resultados economicamente favoráveis.

O emprego do promotor de crescimento associado ao leite gerou um déficit de $\mathrm{R} \$ 11,30$. Resultado similar foi apresentado por Nsahlai et al. (2002), ao verificarem que o ganho com o uso do zeranol foi pequeno em relação ao custo de sua implantação. Entretanto, é importante salientar que a utilização do zeranol promoveu incremento significativo de desempenho que pode contribuir para melhor retorno financeiro em uma segunda etapa de criação dos bezerros.

O Sindicato Nacional dos Pecuaristas (Barros, 2001) estimou que o ganho de peso, a partir do uso de anabolizantes seguros, pode atingir o valor de US\$7,40 por implante ou US\$0,37/arroba, sendo o custo internacional de uma dose de anabolizante xenobiótico de US\$1,20 a 1,40. Considerando o aumento no ganho de peso, pode-se ter redução de custo de até US\$3,40 por arroba, conforme dados projetados por esse órgão. Ainda, de acordo com o Sindicato, estima-se que a relação custo benefício dos anabolizantes xenobióticos no Brasil possa atingir 6,5:1.

T5 foi o que apresentou melhores resultados, promovendo retorno de $\mathrm{R} \$ 25,20$ por animal. Alves e Lizieire (2001) verificaram que um sucedâneo somente torna-se viável se o seu custo for 6,4 vezes menor que o do leite.
Apesar do aumento na quantidade de arroba produzida, T6 apresentou retorno econômico $1,1 \%$ inferior ao T5. O incremento dos custos com a inclusão do óleo degomado e da lecitina de soja, associado ao aumento do consumo de concentrado, foram os responsáveis por esse pior balanço.

A utilização do colostro fermentado adicionado de bicarbonato de sódio possibilitou maior retorno econômico e desempenho tão eficientes quanto aos apresentados pela associação do leite integral com zeranol.

\section{CONCLUSÕES}

O menor custo verificado com os animais tratados com colostro fermentado sugere que o seu uso constitui boa opção para o aproveitamento dos machos em rebanhos leiteiros. O colostro fermentado é eficiente como substituto do leite para bezerros em fase de aleitamento.

\section{REFERÊNCIAS BIBLIOGRÁFICAS}

A CARNE que vem do rebanho leiteiro. Disponível em: <http://www.zebus.com.br>, Acesso em: 01 mar. 2003.

ALVES; P.A.M.; LIZIEIRE, R.S. Teste de um sucedâneo na produção de vitelos. Rev. Bras. Zootec., v.30, p.817-823, 2001.

BARROS, L.A. Detecção de resíduos de zeranol e acetato de trembolona em bovinos mestiços por ELISA. 2001. 39f. Dissertação (Mestrado em Zootecnia) - Escola de Veterinária, Universidade Federal de Minas Gerais, Belo Horizonte.

BIONDI, P. Utilização de machos de raças leiteiras para produção de carne. Zootecnia, v.12, p.27-34, 1978.

CALDAS, F. Vitelo: opção de ganho na exploração leiteira. Balde Branco, n.461, p.3640, 2003.

CAMPOS, O.F.; LIZIEIRE, R.S. Alimentação de bovinos jovens. Cad. Téc. Esc. Vet. UFMG, n.14, 1995.

CASTRO, A.L.M.; CAMPOS, W.E.; MANCIO, A.B. et al. Desempenho e rendimento de carcaça de bezerros alimentados com colostro 
fermentado, associado ao óleo de soja e zeranol. Arq. Bras. Med. Vet. Zootec., v.56, p.193-201, 2004.

EASTRIDGE, M.L.; ROSELER, D.K. Grain intake and growth of pre-weaned dairy calves. Res. Review (Special Circular 163-99), 2003. Disponível $<$ http://ohioline.osu.edu/sc163/sc163_9.html $>$ Acesso: 13 set. 2003.

LOMBARDI, C.T.; CASTRO, A.C.G.; COELHO DA SILVA, J.F. et al. Desempenho de bezerros desaleitados precocemente submetidos a restrição no fornecimento do leite. In: REUNIÃO ANUAL DA SOCIEDADE BRASILEIRA DE ZOOTECNIA, 34., 1997, Juiz de Fora. Anais... SBZ, Juiz de Fora, 1997. p.227229.

LUCCI, C.L. Aspectos principais da alimentação de bezerros. Zootecnia, v.14, p.15-27. 1996.

MEJÍA, J.M.J. Análise da eficiência técnica e econômica do uso de farelo de gérmen de milho no desaleitamento precoce de bezerros. 1995. 108f. Dissertação (Mestrado em Zootecnia)Universidade Federal de Viçosa, Viçosa, MG.

NSAHLAI, I.V.; GREEN H.; BRADFORD, M. et al. The influence of source and level of protein, and implantation with zeranol on sheep growth. Liv. Prod. Sci., v.74, p.103-112, 2002.

RIBEIRO, T.R.; PEREIRA, J.C.; LEÃO, M.I. Tamanho de órgãos e vísceras de bezerros holandeses, para produção de vitelos, recebendo dietas com diferentes níveis de concentrado. Rev. Bras. Zootec., v.30, p.2163-2168, 2001a

RIBEIRO, T.R.; PEREIRA, J.C.; OLIVEIRA, M.V.M. Características da carcaça de bezerros holandeses para produção de vitelos recebendo dietas com diferentes níveis de concentrado. Rev. Bras. Zootec., v.30, p.2154-2162, 2001b.

RINDISIG, R.B. Sour colostrum dilutions compared to whole milk for calves. J. Dairy Sci., v.59, p.1293-1300, 1976.

TEIXEIRA, J.C.; PEREZ, J.R.O.; MORON, I.R. et al. Aproveitamento do macho leiteiro utilizando dietas à base de amirea. Ciênc. Agrotec., v.24, p.203-207, 2000.

VASCONCELOS, A.M.; FAÇANHA, D.A.E.; OLIVO, C.J. et al. Utilização de substituto lácteo no desempenho de bezerros da raça holandesa. In: REUNIÃO ANUAL DA SOCIEDADE BRASILEIRA DE ZOOTECNIA, 35., Botucatu, 1998. Anais... SBZ, Botucatu, 1998. p.68-70. 